\title{
TEACHERS' PARTICIPATION IN CURRICULUM DEVELOPMENT: A CASE STUDY FROM AN ENGLISH PREPARATORY PROGRAM AT A TERTIARY INSTITUTION
}

\section{Lien Thi Hong Do}

\section{Article History}

Received: July 12, 2020

Accepted: September 10, 2020

Published: September 30, 2020

\author{
Keywords \\ Curriculum development, \\ teachers' participation, \\ English preparatory program
}

\author{
International School - Vietnam National University, Hanoi, Vietnam \\ Email: liendth@isvnu.vn
}

\section{INTRODUCTION}

In the world of increasing integration, the transnational labor market and the popularity of undergraduate training programs with English as the medium of instruction (EMI) have made English language learning almost a mandatory matter in higher education. In order to prepare learners for EMI undergraduate programs, it is essential to enhance their English competence. Therefore, an English preparatory program is regarded as a meaningful step offered by a number of tertiary institutions to improve the quality of their EMI programs. The main purpose of the English preparatory program is to equip students with sufficient linguistics knowledge, skills, and abilities for effective communication in both general and academic settings.

In order to implement an effective English preparatory program to a large number of students with a low level in English, it is crucial to view curriculum development as an ongoing process to meet constant changes. In this process, the participation of teachers as the main stakeholders should be taken into careful consideration (Oloruntegbe, 2011).

Results from previous studies showed limited involvement of teachers in the curriculum development process (Wiles \& Bondi, 2007; Carl, 2005; Mullick, 2013). In this regard, it is important to examine teachers' perceptions of their role in developing a curriculum and their actual participation. With the purpose to explore how teachers joined in the curriculum development process of an English preparatory program in a Vietnamese tertiary institution, this case study is aimed to answers two questions: - What are teachers' perceptions of their role in the curriculum development process? - To what extent do teachers have a role in the curriculum development of the English preparatory program?

\section{LITERATURE REVIEW}

\subsection{Curriculum and Curriculum development}

For a training program to be run and objectives to be achieved, a proper curriculum is essential. As defined by UNESCO-IBE (2013), the term "curriculum" refers to a systematic and intentional way of "what, why, how, and how well students should learn". In a broader definition, curriculum refers to the aggregate set of courses and training programs designed and implemented to address specific training needs in an area of specialization taught in a school, college, university, or any educational institution. From a static perspective, a curriculum is associated with documented syllabuses and teaching modules that are designed and sent to schools by the ministry of education or authorized institutions for the purpose of teaching (Kelly, 2009). In a more dynamic point of view, it is seen as 
teaching and instructions offered to students in attempts to improve the selection and organization of school knowledge and associated student learning (Kopweh, 2014, cited in Syomwene, 2020).

Regarding the term "curriculum development", UNESCO-IBE refers it to the "process of designing the national, local or school curriculum" in a planned and systematic manner. Curriculum development is aimed at creating longterm impact. The process includes ongoing updates through evaluation and revision to ensure that the curriculum responds to the current educational needs (UNESCO-IBE, 2011).

Viewing curriculum development as a dynamic process, several models have been proposed (Tyler 1981; Saylor, Alexander \& Lewis, 1981; Taba, 1962; Oliva, 2008, cited in Syomwene, 2020), but in general, the process consists of six basic steps: (1) conducting needs assessment (2) setting general goal and specific objectives, (3) selecting content, (4) sequencing content, (5) organizing learning experiences and (6) evaluating.

\subsection{Teachers' participation onto the curriculum development process}

A curriculum as a blueprint of a training program is the product of different stakeholders. These include teachers, parents, students, administrators, inspectors, recruiters who are affected by the curriculum Lunenburg \& Ornstein (2008); Glickman et al., 2013). Among those stakeholders, teachers as the implementers of the curriculum are keys to develop curriculum thanks to their classroom experiences and perspectives (Marsh \& Willis, 2003; Oliva, 2008).

Some authors have identified a limited role for teachers' participation in the curriculum development process (Wiles \& Bondi, 2007). However, the support for the effective participation of teachers in this process is increasing (Carl, 2005; Oliva, 2008; Voogt et al., 2016). The idea of involving teachers in curriculum development has been initiated for a long time (Handler, 2010). As explained by a number of researchers, teachers who are the closest individuals to students may understand the psychology of their students, be aware of the most suitable teaching methods, learning environments, and assessment techniques in the classroom (Jadhav \& Patankar, 2013). In other words, teachers know what is actually happening in the classroom and can perceive what policy-makers cannot. Therefore, they can "become more than consumers of other designers' works and instead become skillful and able in developing their own curriculum" Zohrabi (2014, p.2033). In practice, policy-makers in several Eastern European and Eastern Asian countries have shared a certain amount of freedom to teachers in terms of curriculum decisions (Erss et al., 2014).

Reflecting on the process of curriculum development, it is argued that teachers can participate in different stages. Regarding assessing learners' needs, Messick and Reynolds (1991) explained that thanks to teachers' proximity to their students, they may well identify and respond to students' needs, which is often a shortcoming of a number of curricula. Teachers can also "initiate recommendations, collect data, do research, connect with parents and other stakeholders, write and create educational curriculum materials, receive feedback, and evaluate the curriculum" (Oliva, 2008, p. 128). As the implementers of curricula, by experiencing the actualization of the teaching activities in the classroom, teachers can also see the flaws of the current curriculum from a more practical view and thus make a great contribution to improving it (Alsubaie, 2016).

The active participation of teachers in the curriculum development process not only directly helps provide a better educational system but also enhances the status of the teaching profession (Klein, 1991) and increase their responsibilities (Posner, 2003).

To summarise, teachers' participation should be considered to be an indispensable part of the curriculum development process rather than a welcome gesture to it (Bolstad, 2004). Without their sufficient level of participation in the process, the chances to successfully implement curriculum greatly diminish (Carl, 2005).

\subsection{The study context}

In Vietnam, English preparatory programs are offered in a number of institutions that provide EMI programs. As regulated by the Ministry of Education and Training of Vietnam, undergraduate students who are enrolled in EMI programs have to prove their English level being equivalent to the B2 level according to the 6-level framework for foreign language competence of Vietnam (Circular No 01/2014/TT-BGDDT and Decree No 86/2018/ND-CP).

The International School, a member of Vietnam National University Hanoi, is regarded as a pioneer in providing EMI undergraduate programs with a number of programs joined with foreign partner universities. To prepare students with good command in English, the school offers an English preparatory program within one year to those students who have not met the requirement for English proficiency. In reality, most students display low levels of English when entering the program. This poses challenges to both teachers and students to reach the required level 
within the time constraint. Therefore, school leaders believe having a good quality curriculum is one of the key factors in achieving this ultimate aim, which can be fulfilled with continuous program evaluation and improvement.

The English preparatory program (EPP) at International School has been run since 2006; however, despite the higher rate of students' enrolment in the school, the frequent changes in the format of the final English proficiency test, which is provided by a third party have made the mission of training students to achieve the target of B2 level challenging. Therefore, as stated by the Board of Deans of the School, the innovative curriculum of the EPP program must ensure that all students reach the B2 level of English in a maximum of one school year. The number of students who are enrolled in the program is expected to be 1000. Most of them have a low level of English, which might be equivalent to A1 or Pre-A1 level according to the 6-level framework for foreign language competence of Vietnam.

To prepare for the school year 2020-2021, the Department of Academic Foundations is in charge of developing and implementing the curriculum. The main people who are accountable for the task are heads of the department including one head and three deputy heads. They are all senior English instructors and have knowledge as well as experience in developing curricula. Within a period of two months for the curriculum to be constructed, the heads of the department had several meetings to analyze the situation including the school requirement, academic context, students' input language, their needs, and human resource. The strengths and weaknesses of the previous curriculum were also thoroughly examined. The heads then came up with a general frame of the curriculum including five English levels with a prescribed general goal as well as specific objectives of each level. The frame was then introduced and explained to all English instructors in the department. The instructors were then divided into different groups for detailed development. The format of the final proficiency test was also informed as a base to select and sequence content as well as to decide relevant teaching and learning activities and assessment.

The process of selecting, sequencing content, and forms of assessment at each level was assigned to groups of instructors. As the program is divided into two groups of levels, foundation levels, and test-preparation levels, each group of levels has one group head. This head is responsible for smaller groups including one leader, full-time and adjunct instructors, who developed detailed syllabus, select and design teaching materials, decide specific learning activities, and assessment format. In this way, the task of curriculum development was managed in a decentralized manner with different layers and corresponding responsibilities. The process of the EPP program was completed within two months after some minor adjustments based on recommendations from expert curriculum developers.

\section{RESEARCH METHODS AND RESULTS}

\subsection{Research methods}

\subsubsection{Participants}

Participants in this study are eight full-time English instructors in the Department of Academic Foundations of the International School, Vietnam Nam National University. All of them were involved in the curriculum development process of EPP. There is some heterogeneity among this group of teachers in terms of career and seniority. All participants in the study were females and all had Masters degree in TESOL. Three of them had less than three years of teaching experience in the program and five of them were seniors who have been teaching in the school for more than ten years

\subsubsection{Data collection}

The study employed a qualitative-interpretative research methodology. The main instrument used for data collection was a semi-structured interview. The interview protocol contained six items, two of which sought for teachers' perception of their role in the curriculum development process; three questions asked for their reflection of actual involvement in developing the curriculum of the English preparatory program, and the last question elicited their recommendations from a management point of view to increase the level of teachers' participation.

To ensure that participants could fully express their opinions and thoughts with confidence, as per the participants' request, interviews were conducted in Vietnamese-the participants' and the researcher's first language. Each interview lasted for twelve to twenty minutes and all were conducted online via Microsoft Teams software. All interviews were recorded and transcribed.

\subsubsection{Data analysis}

The data analysis was conducted in several consecutive steps. The first step involved reading the written transcripts several times to gain a general idea about the views and ideas of the participants in each question asked. In the second step, the transcription of each interview was divided into text fragments for summarizing the general issues and grouped into subcategories for interpretative analysis. The following subcategories were used: 
(a) perception of general participation, (b) perception of specific stages to be involved, (c) actual participation, (d) advantages of participation, (e) disadvantages of participation and (f) suggestions for more participation. In the final step, quotes were selected to relevant subcategories and then translated into English.

\subsection{Research results}

\subsubsection{Teachers' perception of their role in curriculum development process of the English preparatory program}

In order to examine teachers' participation in the curriculum development process, it is important to understand their willingness and driving force to take action. Results from the interviews showed that 7/8 participants expressed their enthusiasm to participate in the process. Only one respondent showed her reluctance when viewing herself as a teacher who merely delivered instructions according to a prescribed curriculum. The reasons are given to their wish to join in the process varied. The most frequently mentioned catalyst was teachers' self-efficacy, meaning the belief of being able to handle the tasks, obligations, and challenges related to their teaching to bring about academic outcomes. As most participants explained, being the teachers who implement the curriculum, it is vital for them to contribute to the process, effectively innovate it to improve students' achievement. For example, teacher GV1 explained, "I want to change and want to contribute to curriculum development so that I can help my students achieve their academic goals". Positive perception of their teaching profession was also mentioned by most participants as a motivator to join in the process. This result is relevant to the findings reported by Şentürk (2019) that the participation in curriculum development can "increased their job satisfaction and the ownership of the work they were doing" (p.19) Apart from one senior teacher who stated that she had knowledge and skills in curricula development, the other seven instructors argued that despite their lack of experience in developing curriculum, with their teaching experience and understanding of the program, they could help decide the most suitable curriculum to their students and teaching context. As GV2 claimed, "I have experience in teaching the program so I clearly understand my students, the program structure and objectives. Thus, I can give a lot of feedback to innovate and update the program". Another explanation highlighted by two instructors was that taking part in curriculum development benefits their teaching as they could have a more thorough understanding of the program to improve their instruction in an easier and more effective way. This finding matches with Boyle and Charles's statement that teachers' involment in curriculum development can help see the shortcomings of the curriculum and better identify the needs of the students (2016). Despite the overall enthusiasm, however, one instructor showed her concern that the participation of teachers in the curriculum development process may make it subjective because as "the insiders" and implementers, teachers may not recognize the flaws of the curriculum that they design due to the lack of a broader view.

A deeper exploration of teachers' viewpoints about which stage in the curriculum development process they should engage in revealed dividing opinions. While three younger respondents (about 3-year experience) supposed that it is necessary for teachers to join in all six mentioned stages of the process, from needs assessment to evaluation, others five senior participants concluded that they should play the main part in selecting and sequencing content, organizing learning experience and a part in the evaluation. This difference in perception might result from young teachers' learned theories and experience of the more senior ones of the mechanism, which they were actually involved.

\subsubsection{Teachers' actual participation in the curriculum development process of the English preparatory program}

Understanding the actual involvement of teachers in curriculum development as well as acknowledging their advantages and obstacles is important to determine a more encouraging approach to increase their participation. As reported by all participants, during the process of developing the EPP curriculum, they were most involved in selecting and sequencing content as well as organizing learning experience. GV7 explained "the goals and objectives have been set by our heads and they are reasonable, so our job is to select and sequence the content in the way that can meet both specific objectives of each level and our students' characteristics". GV6 also acknowledged "our heads leave room for us to select the content which we believe to be the best and even propose various learning activities for our students. We actually can be creative in that way". This result partly reflects Şentürk's finding (2019) that teachers were not often involved in making decisions on the objectives and content. They more frequently contribute to more teaching-related stages including sequencing content, creating teaching materials and selecting learning experience.

Regarding advantages when participating in the EPP curriculum development, the respondents mentioned both subjective and objective aspects. Three prominent supporting factors to the job of curriculum development include 
the understanding of the program structure and required outcome, the relevance of the assigned task with previous experience and the expertise knowledge in curriculum development. For example, GV3 reported "I have been teaching linguistic foundation course for years, so I know what my students need. I also have a large collection of teaching materials which I may choose from, so it is good that I am assigned a job that I can do well". Regarding objective support, all participants show their appreciation of the advice and detailed guidance from their leaders as well as other stakeholders such as expert curriculum developers. The open and sharing atmosphere during group work was considered to be encouraging.

However, the participating instructors also reported a number of obstacles, which may shed light to improve the management of the process. 7/8 respondents supposed that their lack of knowledge and experience in curriculum development was a big disadvantage as it caused confusion when making decisions or reach agreement among group members. GV2 said "I know we have to match the teaching material with the outcomes, but it is hard for me to thoroughly evaluate whether the materials we choose and the way we sequence them is effective because I don't have much experience and background knowledge about developing curriculum"; or GV3 explained "I am new to this process so many of my decision depends on my leaders though sometimes I feel uncomfortable with it". This finding is compatible with that found in several previous studies which reported on the lack of teacher training on curriculum development (Handler, 2010; Alsubaie, 2016; Şentürk, 2019). Other contextual factors were also challenges. 4/7 respondents perceive time constraint as a factor limiting their effectiveness and creativity because "if having more time, our group may seek for more guidance from other experts and find a larger collection of teaching materials" (GV4), or "I was teaching other classes when was asked to do the task. I really need more time to polish the syllabus which I was assigned" (GV5). Finally, the variety of learners and the lack of information about constant change in the format of the final English proficiency were referred to as difficulties.

When asked what kind of support they need to participate more in the curriculum development process, the participants proposed three recommendations. First, with the decentralization mechanism in developing a curriculum, it is important for all participating teachers to understand the overall picture of the program, its objectives as well as detailed operating tasks. Therefore, $5 / 7$ respondents suggest that the project heads should organize more meetings to inform and give guidance to teachers. Communication between layers of management and among group members should be more transparent. GV8 recommended, "I think the project heads should have more meeting with all fulltime and adjunct teachers, so that everyone may understand the common goals as well as their specific responsibilities". Due to the reported lack of professionalism in curriculum development, all participants agreed that they will do the job better if they are given more opportunities to take part in training courses and seminars of the field. Finally, proper monetary and non-monetary incentives to teachers were suggested because "we actually had to do much more job apart from the main teaching profession" (GV5).

\section{DISCUSSION AND CONCLUSION}

The study aimed at examining teachers' perceptions of being involved in the curriculum development process and their actual activities. Using a qualitative research method, the author tried to explore the phenomenon of teachers' involvement in a decentralized project of developing a curriculum for an English preparatory program. Results from semi-structured interviews showed a high level of enthusiasm of respondents toward their role in developing the curriculum because of their self-efficacy and confidence in teaching ability as well as experience. Regarding the process of curriculum development, although most participants believe they can contribute their knowledge, skills, and experience in all stages, their actual participation is mostly limited to selecting and sequencing content and organizing learning experience. Also, despite support from project heads and their understanding of the program, teachers also reported time constraints, lack of expertise, lack of availability of information emerged as the major barriers to teachers' participation. The study recommends that decentralization of the curriculum design process, the provision of training opportunities, and various types of incentives are appropriate for increasing the level of teachers' engagement in curriculum development.

\section{REFERENCES}

Alsubaie, M. A. (2016). Curriculum development: Teacher involvement in curriculum development. Journal of Education and Practice, 7(9), 106-107.

Baş, G. \& Şentürk, C. (2019). Teachers' voice: Teacher participation in curriculum development process. Inquiry in Education, 11(1), 1-31. 
Bolstad, R. (2004). School-based curriculum development: Principles, processes, and practices. Wellington, New Zealand: New Zealand Council for Educational Research.

Carl, A. (2005). The "voice of the teacher" in curriculum development: A voice crying in the wilderness. South African Journal of Education, 25(4), 223-228.

Erss, M., Mikser, R., Löfström, E., Ugaste, A., Rõuk, V., \& Jaani, J. (2014). Teachers' views of curriculum policy: The case of Estonia. British Journal of Educational Studies, 62, 393-411. doi:10.1080/ 00071005.2014 .941786

Glickman, C. D., Gordon Glickman, C. D., Gordon, S. P., \& Ross-Gordon, J. M. (2013). The basic guide to supervision and instructional leadership ( $3^{\text {rd }}$ ed., pp. 250-262). Boston: Pearson.

Handler, B. (2010). Teacher as curriculum leader: A consideration of the appropriateness of that role assignment to classroom-based practitioners. International Journal of Teacher Leadership, 3(3), 32-42.

Jadhav, M. S., \& Patankar, P. S. (2013). Role of teachers' in curriculum development for teacher education. Paper presented at the National Conference on Challenges in Teacher Education, Physical Education and Sports, Kolhapur, India.

Kelly, A. V. (2009). Curriculum Theory and Practice ( $6^{\text {th }}$ Edition). Los Angeles: Sage Publications.

Klein, M. F. (1991). A conceptual framework for curriculum decision making. In M. Klein (Ed.), The politics of curriculum decision making: Issues in centralizing the curriculum (pp. 24-41). Albany, NY: State University of New York.

Lunenberg, F., \& Ornstein, A. C. (2008). Educational administration: Concepts and practices (5 ${ }^{\text {th }}$ ed.). Belmont, CA: Wadsworth.

Marsh, C. J., \& Willis, G. (2003). Curriculum: Alternative approaches, ongoing issues (3 ${ }^{\text {rd }}$ ed.). Columbus, OH: Merrill.

Messick, R. G., \& Reynolds, K. E. (1991). Middle level curriculum in action. New York, NY: Longman.

Mullick, H. (2013). Voices imprisoned within classrooms: A critical approach to curriculum development and teacher voice on a preparatory year English language program in the Kingdom of Saudi Arabia. International Journal of Bilingual \& Multilingual Teachers of English, 1(2), 37-48.

Oliva, P. F. (2008). Developing the curriculum ( $7^{\text {th }}$ ed.). Boston, MA: Pearson.

Oloruntegbe, K. O. (2011). Teachers' involvement, commitment and innovativeness in curriculum development and implementation. Journal of Emerging Trends in Educational Research and Policy Studies, 2, 443-449.

Posner, G. J. (2003). Analyzing the curriculum ( $3^{\text {rd }}$ ed.). New York, NY: McGraw-Hill.

Syomwene, A. (2020). Curriculum theory: Practice and functions. European Journal of Education Studies, 7(1), 326337. doi:10.5281/zenodo.3718433

UNESCO International Bureau of Education (2011). Towards a quality education for all: the national curriculum framework 2011. Retrieved from https://unesdoc.unesco.org/ark:/48223/pf0000212722?posInSet=1\&queryId= e5867cf3-4276-4168-a345-0909605119d8

UNESCO International Bureau of Education (2013). Glossary of curriculum terminology. Retrieved from https://unesdoc.unesco.org/ark:/48223/pf0000223059?posInSet=2\&queryId=20e6eead-5e88-4e0a-b67a-ef31428cc6f7

UNESCO, (2014). EFA Global Monitoring Report 2013/4 - Teaching and Learning: Achieving Quality for All. Available at http://unesdoc.unesco.org/images/0022/002256/ 225660e.pdf

Voogt, J. M., Pieters, J. M., \& Handelzalts, A. (2016). Teacher collaboration in curriculum design teams: effects, mechanisms, and conditions. Educational Research and Evaluation, 22(4), 121-140.

Wiles, J., \& Bondi, J. (2007). Curriculum development: A guide to practice ( $7^{\text {th }}$ ed.). Upper Saddle River, NJ: Pearson/Merrill Prentice Hall.

Zohrabi, M. (2014). Promoting teacher development through an interactive approach to curriculum development. Procedia-Social and Behavioral Sciences, 98, 2025-2034. doi:10.1016/j.sbspro.2014.03.638 